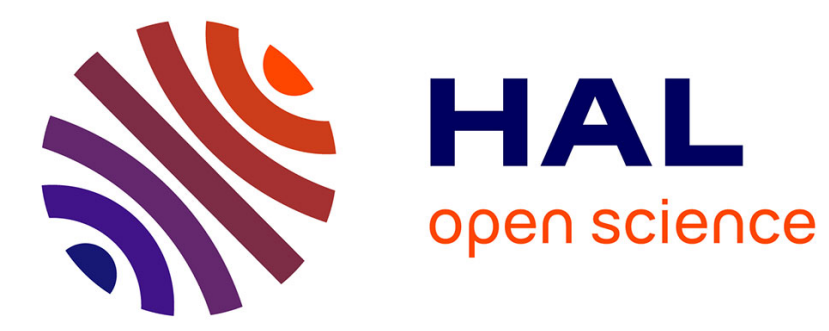

\title{
Activity-dependent translocation of neurogranin to neuronal nuclei
}

Alberto Garrido-García, Beatriz Andrés-Pans, Lara Duran-Trio, F. Javier

Díez-Guerra

\section{- To cite this version:}

Alberto Garrido-García, Beatriz Andrés-Pans, Lara Duran-Trio, F. Javier Díez-Guerra. Activitydependent translocation of neurogranin to neuronal nuclei. Biochemical Journal, 2009, 424 (3), pp.419429. 10.1042/BJ20091071 . hal-00479228

\section{HAL Id: hal-00479228 \\ https://hal.science/hal-00479228}

Submitted on 30 Apr 2010

HAL is a multi-disciplinary open access archive for the deposit and dissemination of scientific research documents, whether they are published or not. The documents may come from teaching and research institutions in France or abroad, or from public or private research centers.
L'archive ouverte pluridisciplinaire HAL, est destinée au dépôt et à la diffusion de documents scientifiques de niveau recherche, publiés ou non, émanant des établissements d'enseignement et de recherche français ou étrangers, des laboratoires publics ou privés. 


\title{
ACTIVITY-DEPENDENT TRANSLOCATION OF NEUROGRANIN TO NEURONAL NUCLEI
}

\author{
Alberto Garrido-García, Beatriz Andrés-Pans, Lara Durán-Trío and F. Javier Díez-Guerra* \\ Departamento de Biología Molecular and Centro de Biología Molecular Severo Ochoa \\ (Consejo Superior de Investigaciones Científicas - Universidad Autónoma de Madrid) \\ Universidad Autónoma de Madrid \\ E-28049, Madrid, Spain
}

Short Title: Neurogranin translocation to neuronal nuclei

\author{
*Address correspondence to: \\ Dr. F. Javier Díez-Guerra \\ Departamento de Biología Molecular \\ Centro de Biología Molecular Severo Ochoa (CSIC-UAM) \\ Universidad Autónoma de Madrid \\ C/ Nicolás Cabrera, 1 \\ 28049 Madrid, SPAIN \\ Tel. +3491 1964612 \\ Fax. +34911964420 \\ e-mail: fjdiez@cbm.uam.es
}


Neurogranin translocates to neuronal nuclei

\section{Synopsis.-}

Long-term changes of synaptic plasticity depend on protein synthesis and transcription. Neurogranin $(\mathrm{Ng})$ is a small protein concentrated at dendrites and spines of forebrain neurons, involved in synaptic plasticity through the regulation of calmodulin $(\mathrm{CaM})$ mediated signalling. $\mathrm{Ng}$ presents a central IQ motif that mediates its binding to $\mathrm{CaM}$ and phosphatidic acid (PA) and that can be phosphorylated by protein kinase $\mathrm{C}(\mathrm{PKC})$. Here, we report that $\mathrm{Ng}$ displays a strong nuclear localization when expressed in cell lines and hippocampal neurons, either alone or fused to green fluorescent protein (GFP-Ng). Further, using subcellular fractionation and immunocytochemical techniques, we were able to localize endogenous $\mathrm{Ng}$ in the nuclei of rat forebrain neurons. Nuclear localization of $\mathrm{Ng}$ depends on its IQ motif and is reduced by binding to cytoplasmic CaM. Also, PKC stimulation induces a transient nuclear translocation of $\mathrm{Ng}$ in acute hippocampal slices. A similar translocation is observed in neurons of the cerebral cortex and hippocampus after the induction of generalized seizures in adult rats. In summary, the data presented here show that a fraction of rat brain $\mathrm{Ng}$ is localized in the neuronal nuclei and that synaptic activity regulates its translocation from the cytoplasm. The possible involvement of $\mathrm{Ng}$ in the regulation of intranuclear $\mathrm{Ca}^{2+} / \mathrm{CaM}$ dependent signalling and gene expression is discussed.

Key words: neurogranin, calmodulin, cell nucleus, protein kinase C.

Abbreviations used:

neurogranin $(\mathrm{Ng})$, calmodulin $(\mathrm{CaM})$, protein kinase $\mathrm{C}(\mathrm{PKC})$, phosphate buffer $(\mathrm{PB})$, phosphatebuffered saline (PBS), 3,3'-diaminobenzidine (DAB), foetal calf serum (FCS), immunofluorescence (IF), Triton X-100 (TX-100), intraperitoneal (i.p.), 12-O-tetradecanoylphorbol-13-acetate (TPA), nuclear localization signal (NLS), bisyndolil-maleimide-I (Bis-I), okadaic acid (OKA), phosphatidic acid (PA), electron microscopy (EM), region of interest (ROI), days in vitro (DIV), 2,3-dimercapto-1propanol (BAL), 1,2-Ethanedithiol (EDT 2 ) 
Neurogranin translocates to neuronal nuclei

\section{INTRODUCTION}

Long term changes in synaptic connection strength depend on protein synthesis and transcription $[1,2]$ and several signalling pathways leading to transcriptional activation have been implicated in learning and memory [3-5]. However, knowledge of synapse-to-nucleus signalling in neurons grows slowly and few molecules entering the nucleus upon stimulation of neuronal activity have been identified. Among them, there are transcription factors such as nuclear factor kappa B (NF-кB) [6] and nuclear factor of activated T-cells (NFAT) [7], enzymes such as extracellular signal-regulated kinase 2 (ERK2) [8], proline-rich tyrosine kinase 2 (PYK2) [9] and the class II histone deacetylases HDAC4 and HDAC5 [10], and other proteins such as calmodulin (CaM) [11], AIDA-1 [12] , profilin [13] and, more recently, thymosin $\beta 15$ [14] and Jacob [15].

Neurogranin $(\mathrm{Ng})$, a small protein identified in brain [16-18], is a post-synaptic protein kinase $\mathrm{C}$ (PKC) substrate abundantly expressed in the cerebral cortex, hippocampus, amygdala and basal ganglia. $\mathrm{Ng}$ binds $\mathrm{CaM}$ in the absence or at low levels of $\mathrm{Ca}^{2+}$ and releases it at micromolar or higher concentrations. Ng phosphorylation at serine 36 by PKC prevents its binding to CaM $[16,19]$. More recently, it has been shown that $\mathrm{Ng}$ binds to phosphatidic acid (PA) and associates to cellular membranes [20]. Ng interactions are mediated by a central 15-20 amino acid stretch, termed IQ-motif, that shapes an amphiphilic $\alpha$-helix rich in basic and hydrophobic residues and shares strong homology to the IQ motif present in GAP-43, an axonal protein abundantly expressed in developing and regenerating neurons [21].

There is a relationship between $\mathrm{Ng}$ expression, synaptic plasticity and remodelling of neuronal connections. In the rat forebrain, $\mathrm{Ng}$ expression develops postnatally and peaks during the third week of life, coincident with a period of intense synaptogenesis [22, 23]. In canaries and zebra finches, $\mathrm{Ng}$ expression is high in the song nucleus Area $\mathrm{X}$ during the juvenile song learning period and decreases noticeably in the adults, who exhibit a robust stability of the song control circuit [24]. Further, $\mathrm{Ng}$ knock-out mice show severely reduced performance in the Morris water maze, deficits in highfrequency-induced long-term potentiation (LTP) in area CA1 and significantly decreased intracellular $\mathrm{Ca}^{2+}$ responses after strong tetanic stimulation [25]. Actually, Ng-deficient mice have lower amounts of phosphorylated $\mathrm{Ca}^{2+} / \mathrm{CaM}$-dependent protein kinase II (CaMKII) in their brains [26, 27], suggesting an attenuated signalling through $\mathrm{Ca}^{2+} / \mathrm{CaM}$-mediated pathways.

In neurons, $\mathrm{Ng}$ is localized in small aggregates distributed in cell bodies and dendrites, and concentrates at the perinuclear region and dendritic spines [28]. $\mathrm{Ng}$ sorting into the somatodendritic compartment most likely depends on the dendritic targeting of its mRNA [29, 30] and its local translation [31, 32]. Earlier work already described the presence of $\mathrm{Ng}$ in the nucleoplasm of cerebral cortex [23] and striatal [28] neurons. However, later studies using subcellular fractionation [33] or immunocytochemical [34] methods did not find $\mathrm{Ng}$ in the neuronal nucleus.

In this study, we show that $\mathrm{Ng}$ is present at the nucleoplasm of neurons and moves from the cytoplasm to the nucleus in a synaptic activity-dependent manner. In the nuclear translocation mechanism described, Ng IQ motif and its interaction with CaM seem to play an important role. Altogether, these results open the possibility that $\mathrm{Ng}$, tightly related to synaptic plasticity, may act as a nuclear regulator of $\mathrm{Ca}^{2+} / \mathrm{CaM}$ dependent signalling, leading to fine tuning of transcriptional activity in neurons. 
Neurogranin translocates to neuronal nuclei

\section{EXPERIMENTAL}

\section{Antibodies and plasmids}

$\mathrm{Ng}$ antibodies Ab205 and Ab756 have been described before [20] and were used as clarified sera for immunoblot or affinity-purified against the relevant immunogens for immunofluorescence (IF). Rhodamine-labelled affinity-purified Ng Fab (Ng Rhod-Fab) was obtained from Ab756 IgG, by papain digestion, Fc fragment removal with protein-A-sepharose, labelling with 5-6-carboxy-tetramethylrhodamine-N-hydroxysuccinimide (Sigma) and affinity purification in a Ng-affigel column using standard protocols and labelling procedures [35]. Monoclonal mouse antibody to CaM was kindly provided by Dr. J. M. McDonald (University of Alabama, Birmingham). The cDNAs for Ng, NgC3,4,9S, Ng-S36A and Ng-S36D were a generous gift of Dr. Dan Gerendasy (Scripps Institute, La Jolla). The cDNA for Ng-I33Q was donated by Dr. Dan Storm (University of Washington). Ng-IQless, double-Ng $(\mathrm{dNg})$ and 4 Cys-Ng cDNAs were made by PCR cloning in pcDNA3. Ng-IQless lacks residues 31-45 of the $\mathrm{Ng}$ rat sequence. Double-Ng consists of two complete Ng polypeptides assembled in tandem. 4Cys-Ng features an optimized biarsenical-binding tetracysteine motif (MDFLNCCPGCCMEPSAC..) (shown in bold) inserted at the $\mathrm{N}$-terminal of $\mathrm{Ng}$ [36]. cDNAs of $\mathrm{Ng}$ and mutants were subcloned (HindIII-BamHI) into pcDNA3 and psGFP2-C1 vector, kindly provided by Dr. TW Gadella [37]. The rat cDNA of CaM was cloned by PCR into pcDNA3 (pcDNA3-CaM).

\section{Immunocytochemistry}

Animals were deeply anesthetized by intraperitoneal (i.p.) administration of pentobarbital and transcardially perfused with cold $0.12 \mathrm{M}$ phosphate buffer $\mathrm{pH} 7.3$ (PB) for $5 \mathrm{~min}$ and then cold $4 \%$ paraformaldehyde (PFA) in PB for 30 minutes. Brain pieces were post-fixed overnight in the same fixative and $100 \mu \mathrm{m}$ sections cut on a vibratome. Endogenous peroxidase was blocked with $0.1 \% \mathrm{H}_{2} \mathrm{O}_{2}$ in PB (20 min) and free-floating sections successively incubated in a) 5\% heat-inactivated horse serum (HS), $0.2 \%$ (w/v) saponin in PB for 2 hours, b) affinity-purified Ng antibody (Ab205, 1:500) in the same buffer overnight, c) biotinylated donkey anti-rabbit immunoglobulin $\mathrm{G}$ ( $\operatorname{IgG})$ (1:200) for 2 hours and d) $\mathrm{ABC}$ Elite reagent (Vector, Burlingame, $\mathrm{CA}$ ) for 1 hour. Immunostaining was visualized using 3,3'-diaminobenzidine (DAB) (Sigma) and $\mathrm{H}_{2} \mathrm{O}_{2}$ in PB. Non-specific staining was monitored in sections where no primary or no biotinylated secondary antibody was added. Sections were then either dehydrated and mounted with Eukitt (Merck) for wide field light microscopy or enhanced with osmium tetroxide and cut in an ultramicrotome to obtain semithin sections $(1 \mu \mathrm{m}$ thick) that were observed at the optical microscope and further cut to obtain ultrathin sections $(60-100 \mathrm{~nm}$ thick) that were analyzed by electron microscopy (EM) (JEOL JEM1010) [38]. Images were captured with a Photometrics Coolsnap FX digital camera attached to a Zeiss Axiovert200M microscope or, for EM, with a Gatan BioScan camera.

\section{Cell culture and transfection}

NIH-3T3, HEK-293 and Hela cells were grown in DMEM supplemented with 10\% fetal calf serum (FCS), $1 \mathrm{mM}$ glutamine and antibiotics (penicillin and streptomycin at $50 \mathrm{U} / \mathrm{ml}$ ). For transfection, 1.5 $\mathrm{x} 10^{5}$ cells were plated in P35 dishes containing (or not) 4 round coverslips and the following day transfected with $1 \mu \mathrm{g}$ of vector DNA and lipofectamine 2000 (2:1 ratio to DNA) in OptiMem for 150 $\min$. The cells were returned to their normal growth medium and used 24-48 hours later. ReAsH-EDT 2 labelling of cells expressing 4Cys-Ng was done as described [39]. Briefly, cells were rinsed twice with Hank's medium (137 mM NaCl, $5.3 \mathrm{mM} \mathrm{KCl}, 0.45 \mathrm{mM} \mathrm{KH}_{2} \mathrm{PO} 4,0.35 \mathrm{mM} \mathrm{Na}_{2} \mathrm{HPO}_{4}, 1.25 \mathrm{mM} \mathrm{CaCl}_{2}$, $0.8 \mathrm{mM} \mathrm{MgSO}_{4}, 1 \mathrm{mM} \mathrm{NaHCO} 3,1 \mathrm{mM}$ pyruvate, $0.6 \%$ D-glucose and $10 \mathrm{mM}$ HEPES pH 7.3), incubated at $37^{\circ} \mathrm{C}$ for $60 \mathrm{~min}$ in the same medium containing $1 \mu \mathrm{M} \mathrm{ReAsH}$ and $2 \mu \mathrm{M} \mathrm{EDT}_{2}$, washed $4 \mathrm{x}$ 2 min with $250 \mu \mathrm{M}$ 2,3-dimercapto-1-propanol (BAL) in Hank's medium and returned to their original culture medium. 4Cys-Ng was recognized by affinity purified Ng antibodies Ab205 and Ab756, either by immunoblot and IF. Specific in vivo labelling of tetracysteine motifs was assessed using cells expressing mCFP-tetraCys [40], a cyan fluorescent protein with an optimized tetracysteine motif at its C-terminus (kindly provided by Dr. J. Llopis, CRIB-UCLM). Cultures of hippocampal neurons were prepared from E18 rat embryos essentially as described [41] and maintained in Neurobasal medium with B27 supplement and Glutamax. At DIV 3, $2 \mu \mathrm{M}$ Ara-C (cytosine arabinoside) was added to the culture medium and $50 \%$ of the medium volume was replaced once a week. For biochemical studies, 
Neurogranin translocates to neuronal nuclei

neurons were seeded at 35.000 cells $/ \mathrm{cm}^{2}$ in P35 plates and at 15.000 cells $/ \mathrm{cm}^{2}$ for IF $(18 \mathrm{~mm}$ coverslips in 12x multiwell plates). Transfection of cultured neurons was performed at DIV 7 using lipofectamine 2000 .

\section{Immunofluorescence}

Coverslips used for IF were cleaned in $65 \%$ nitric acid overnight, extensively washed with distilled water and heat-sterilized at $120^{\circ} \mathrm{C}$ in an oven. Unless stated, the IF procedure was as follows (normal IF): After a quick rinse with Hank's medium, cells were fixed with 2\% PFA in Hank's medium for 20 min, washed (x3) with PBS and incubated in $0.1 \mathrm{M}$ glycine/PBS to inactivate free aldehydes (15 min). Blocking non-specific binding and permeabilization was achieved by incubating in blocking buffer (5\% heat-inactivated horse serum, $0.2 \%$ (w/v) Triton X-100 (TX-100) in PBS) for 30 min. Primary and secondary antibody incubations were done in blocking buffer for 90 and $45 \mathrm{~min}$, respectively, followed by three 5 min washing steps in PBS. To visualize cell nuclei, an additional incubation with To-Pro3 $(1: 500,30 \mathrm{~min})$ was made, followed by extensive washing. Finally, coverslips were rinsed in distilled water and mounted in Mowiol. Negative controls were made by omitting the primary antibody. Visual inspection and image acquisition was mostly done using 63x PlanApo 1.4 NA and 100x PlanApo 1.4 NA objectives in a Zeiss Axiovert200M microscope equipped with a Photometrics Coolsnap FX monochrome camera and MetaMorph 6.1 software (Universal Imaging). In addition, confocal images were acquired with a Zeiss LSM 510 confocal microscope using multitrack scanning mode, at $1024 \times 1024$ (no zoom and 2x averaging) using the following laser lines: $488 \mathrm{~nm}(30 \mathrm{~mW}$ Argon, 8 $10 \%), 543 \mathrm{~nm}(1.2 \mathrm{~mW} \mathrm{He}-\mathrm{Ne}, 30 \%)$ and $633 \mathrm{~nm}(5 \mathrm{~mW}$ HeNe, 50\%). Digital image processing (averaging, background subtraction, shading correction) and montage were done using ImageJ software (Rasband, W.S., National Institutes of Health, Bethesda, MA, USA, http://rsb.info.nih.gov/ij/, 19972009). To quantify colocalization and Pearson's coefficients, images were registered using the TurboReg plugin (http://bigwww.epfl.ch/thevenaz/turboreg/) and then analyzed with the intensity correlation analysis and colocalization threshold plugins (http://www.uhnresearch.ca/facilities/wcif/imagej/).

\section{Determination of $\mathrm{Ng} \mathrm{Nuc/Cyto} \mathrm{ratios} \mathrm{by} \mathrm{image} \mathrm{analysis}$}

Cells expressing GFP, GFP-Ng or GFP-Ng mutants were fixed and their nuclei counterstained with ToPro3. Cells exhibiting an unusual size, morphology or expression levels were discarded. Using the confocal microscope and the $63 \mathrm{X}$ lens, a single optical slice was chosen from each imaged cell at the height where the nucleus exhibited the longest diameter (Figure 4A). The images obtained using 488nm (GFP) and 633nm (ToPro3) laser excitation were background subtracted and above-background areas selected and used to outline the cellular and nuclear perimeters, respectively. The nuclear region (Nuc) was subtracted from the total cell area to obtain the cytoplasmic region (Cyto). Finally, the mean fluorescence intensity elicited by $488 \mathrm{~nm}$ excitation was determined for both regions and the Nuc/Cyto ratio calculated.

\section{Hippocampal slices, tissue and cell culture extracts}

Adult male rats were sacrificed according to the local and EEC rules and their brains quickly removed, cooled and cleaned from meninges and blood clots. Both hippocampi were carefully exposed, unrolled along the hippocampal fissure, dissected out and then cut into $350 \mu \mathrm{m}$ slices using a McIlwain tissue chopper. The slices were equilibrated for $60 \mathrm{~min}$ in air bubbling Hank's medium and transferred to flatbottom tubes ( 3 slices per tube), containing $0.5 \mathrm{ml}$ of fresh oxygenated Hank's medium. For treatments, drugs were added directly to the medium and the slices incubated at $30^{\circ} \mathrm{C}$ with shaking. Total extracts of hippocampal slices, fresh tissue or cell cultures were obtained by homogenization in $2 \%$ SDS, $5 \mathrm{mM}$ Tris-HCl pH 6.8, $1 \mathrm{mM}$ EDTA and $10 \mathrm{mM}$ 2-mercaptoethanol, heated at $90^{\circ} \mathrm{C}(2 \mathrm{~min})$ and centrifuged.

\section{Immunoblots}

Aliquots from extracts were mixed with electrophoresis sample buffer, heated at $90^{\circ} \mathrm{C}$ for $1 \mathrm{~min}$, separated by SDS-PAGE and processed for immunoblot as described [42]. Primary antibodies used were: $\mathrm{Ng} \mathrm{Ab756} \mathrm{(rabbit,} \mathrm{1:40.000),} \mathrm{phospho-} \mathrm{Ng}(\mathrm{Ser} 36)$ (rabbit, 1:5.000, Upstate), anti-GFP (mouse, 1:10.000, Roche) and anti-CaM (mouse, 1:20.000). Immunoreactive bands were visualized using 
biotinylated secondary antibodies (1:5.000, Jackson), Vectastain ABC Elite (Vector) and enhanced chemiluminescence detection (ECL kit, Amersham) or DAB/ $\mathrm{H}_{2} \mathrm{O}_{2}$.

\section{Nuclear extracts}

The Ne-Per reagents (Pierce) were used to prepare nuclear and cytoplasmic extracts from rat brain tissue and cell cultures. We checked other methods to prepare nuclei enriched fractions, including isolation of nuclei using a sucrose density barrier [43]. With all of them, highly purified nuclear fractions were obtained, as demonstrated by the distribution of nuclear and cytoplasmic markers. In general, a compromise between the purity of isolated nuclei and the time of fractionation needs to be reached, especially for small size components that may leak from nuclei during the procedure. In our hands, the Ne-Per reagents consistently gave the lowest values of nuclear $\mathrm{Ng}$ in brain tissue and good separation of nuclear and cytoplasmic markers (not shown).

\section{Pentylenetetrazole treatment}

Adult rats (3 months old) were injected with pentylenetetrazole (PTZ, Sigma) in saline at $45 \mathrm{mg} / \mathrm{kg}$ (i.p.) of body weight. Control animals received the same volume of saline. Treated animals developed strong convulsions, most of them at 2-3 min after PTZ injection, that were rated of degree 5, according to the scale of McIntyre and Racine [44]. In the following 10-15 min, some animals had more seizures, coming in short periods and declining in strength, and then gradually entered into a period of rigidity. Animals that suffered severe and prolonged seizures were administered a single dose of thiopental (25 $\mathrm{mg} / \mathrm{kg}$, ip) and separated from the experimental group. Rats were sacrificed at several times after PTZ injection, their brains removed and the hippocampus and cerebral cortex quickly dissected, weighed and frozen on dry ice. Nuclear and cytoplasmic extracts were separated from tissue samples using the NePer kit (Pierce) and analyzed by immunoblot.

\section{General Methods}

Restriction-enzyme digestions, DNA ligations, site-directed mutagenesis and other recombinant DNA procedures were performed using standard protocols. All DNA constructs were verified by DNA sequencing.

\section{Statistics}

Experiments were normally repeated independently at least three times and typical results from IFs and immunoblots are shown. To evaluate the differences between experimental groups, unpaired t-test (twotailed) was used. Unless stated, means \pm S.E.M. are represented. The differences were considered statistically significant when $\mathrm{P}<0.05(*, \mathrm{P}<0.05 ; * *, \mathrm{P}<0.01 ; * * *, \mathrm{P}<0.001)$. 
Neurogranin translocates to neuronal nuclei

\section{RESULTS}

\section{Ng accumulates at the cell nucleus}

A number of GFP-Ng constructs were prepared to study the dynamics of $\mathrm{Ng}$ subcellular localization. Following GFP-Ng expression, a strong nuclear localization was noticed, which contrasted with the description of $\mathrm{Ng}$ as a predominantly cytoplasmic protein [33]. To investigate it, the intracellular distribution obtained from direct GFP-Ng fluorescence was compared that derived of indirect IF with $\mathrm{Ng}$ antibodies. As shown in Figure 1A (top row), Ng immunoreactivity in GFP-Ng expressing cells is observed at the cytoplasm but not in the nucleus, whereas GFP-Ng fluorescence is strong in the nucleus and less evident at the cytoplasm. This puzzling result was also obtained with different cell lines (HEK293, Hela, NIH-3T3), cultured hippocampal neurons (supplemental figure 1), different $\mathrm{Ng}$ antibodies (Ab756 and Ab205) and constructs of $\mathrm{Ng}$ fused to several fluorescent proteins (data not shown). In addition, proteolysis of GFP-Ng was discarded by immunoblot analysis of total cell extracts with GFP and $\mathrm{Ng}$ antibodies (supplemental figure 1).

Since GFP-Ng remains intact, it could be that $\mathrm{Ng}$ antibodies were not completely detecting GFP-Ng due to either poor antibody penetration or to epitope masking. To improve $\mathrm{Ng}$ titration, we used two strategies: i) extend primary antibody incubations to 18 hours or longer (long IF) and ii) incubate live cells with $0.05 \%$ saponin for $30 \mathrm{sec}$ before fixation (sap + long IF), to extract cytoplasmic material and facilitate antibody access. As shown in Figure 1A (middle row), longer primary antibody incubations allowed us to see some nuclear $\mathrm{Ng}$ immunostaining. Further, saponin permeabilization led to a nearly complete loss of cytoplasmic immunoreactivity, but also to enhanced detection in the nucleus (Figure $1 \mathrm{~A}$, bottom row). These results suggest that intact GFP-Ng is actually present in the nucleoplasm. However, they do not demonstrate the nuclear localization of $\mathrm{Ng}$, since $\mathrm{Ng}$ localization could be altered by "GFP tagging". To investigate this, we used the "long IF" procedure with $\mathrm{Ng}$ expressing cells and found $\mathrm{Ng}$ immunoreactivity in the nuclei (Figure $1 \mathrm{~B}$, middle row). More clear evidence was obtained after saponin permeabilization, since $\mathrm{Ng}$ expressing cells exhibited strongly fluorescent nuclei, although with most of the immunoreactivity washed out from the cytoplasm (Figure 1B, bottom row). We also found that poor detection of nuclear Ng in "normal IF" conditions was possibly due to limited antibody penetration and not epitope masking, since similar results were obtained using GFP expressing cells and GFP antibodies (supplemental figure 2).

Since previous reports had been somehow contradictory [23, 28, 33, 34], we looked for additional evidence to support the nuclear localization of $\mathrm{Ng}$ and, at the same time, to validate GFP-Ng as $\mathrm{Ng}$ reporter. We prepared a construct for $4 \mathrm{CysNg}$, a $\mathrm{Ng}$ mutant that carries an optimized tetracysteine tag at its $\mathrm{N}$-terminus, which minimally disrupts its sequence and size [36]. 4Cys-Ng, which can be visualized after ReAsH labelling, showed a strong nuclear accumulation that could not be detected by "normal IF", as expected (Figure 1C). A different approach was to use smaller probes to titrate $\mathrm{Ng}$, since they should have better intracellular penetration. Monovalent Fab fragments from immune sera retain the ability to bind to their original epitope and are three times smaller than the parent immunoglobulin molecules. Thus, an affinity purified rhodamine-labelled Fab fragment (Ng Rhod-Fab) was prepared from Ab756 and used to localize Ng in GFP-Ng expressing cells. As shown in Figure 1D, the labelling profile of $\mathrm{Ng}$ Rhod-Fab was practically identical to that derived from the fluorescence of GFP-Ng (the Pearson's coefficient for the colocalization was 0.996), indicating that the Fab fragment achieves higher titration levels than the parent IgG. This additional evidence further supports the view that $\mathrm{Ng}$ accumulates in cell nuclei and that GFP-Ng derived fluorescence accurately reports the intracellular localization of $\mathrm{Ng}$. Finally, when Ng Rhod-Fabs were used with $\mathrm{Ng}$ expressing cells, $\mathrm{Ng}$ accumulation was also observed in the nucleus (supplemental figure 2).

Then we investigated whether endogenous $\mathrm{Ng}$ also exhibits nuclear localization. For this, we measured $\mathrm{Ng}$ levels in purified nuclear and cytoplasmic fractions from striatum, hippocampus and cerebral cortex. We found that $\mathrm{Ng}$ is present in the nuclear fractions of the three regions analyzed and that its levels gradually increase from postnatal day 7 to 32 and then decline slightly in the adult (Figure 2). Intracellular $\mathrm{Ng}$ localization was also studied by immunocytochemistry followed by optical or electron microscopy imaging. $\mathrm{Ng}$ expression is high in the forebrain [22] and, in particular, in the hippocampus 
Neurogranin translocates to neuronal nuclei

and in layers II-IV of the cerebral cortex (Figure 3A). $\mathrm{Ng}$ could be clearly detected in nuclei of hippocampal (Figure 3E, thick sections) and cerebral cortex neurons (Figures 3B-D, semithin sections). Interestingly, $\mathrm{Ng}$ concentration varied markedly in the nuclei of adjacent neurons (Figures 3C-D). This was also observed in CA2 neurons by EM imaging (Figures $3 \mathrm{~F}$ and $3 \mathrm{G}$ ), confirming that the nuclear levels of $\mathrm{Ng}$ can be differentially regulated in neighbouring neurons.

\section{Nuclear accumulation of $\mathrm{Ng}$ requires an intact IQ motif}

We then studied which part of the $\mathrm{Ng}$ sequence is more relevant for its nuclear localization. We first analyzed $\mathrm{Ng}$ levels in nuclear and cytoplasmic fractions from cells expressing several $\mathrm{Ng}$ mutants. However, the comparison was difficult due to differences in transfection efficiency and expression levels. On the other hand, observation at the fluorescence microscope suggested marked differences of nuclear localization among the GFP-Ng mutants. To quantify them, we used a simple procedure to measure the mean intensity values of fluorescence in the nuclear (Nuc) and cytoplasmic (Cyto) regions of cells expressing GFP or GFP-Ng and mutants (Figure 4B). These values were used to calculate the Nuc/Cyto mean intensity ratio (Experimental section and Figure 4A). As shown in Figure 4C, GFP-Ng expressing cells showed a Nuc/Cyto ratio 2.5 times greater than that of GFP, suggesting that $\mathrm{Ng}$ carries signals that promote its nuclear accumulation. The fact that GFP-dNg, which features two $\mathrm{Ng}$ molecules assembled in tandem, displayed a Nuc/Cyto ratio 3.5 times greater than that of GFP further supported this view. On the other hand, the deletion of the IQ motif (GFP-Ng-IQless) resulted in lower Nuc/Cyto ratio values, significantly lower than those of GFP-Ng and similar to those of GFP, suggesting that the IQ motif carries the relevant signal needed for nuclear accumulation. It should be noted that the Cterminus of $\mathrm{Ng}$ IQ motif $\left(\mathrm{R}_{43} \mathrm{KKIK}\right)$ shows a striking similarity with previously described nuclear localization signals (NLS) [45]. Addition of leptomycin B (25 nM, up to 6 hours), a potent and specific nuclear export inhibitor, did not modify the Nuc/Cyto ratios of GFP, GFP-Ng, GFP-dNg and GFP-NgIQless (data not shown), suggesting that nuclear export mechanisms were not involved. Other GFP-Ng point mutants studied showed ratios similar to that of GFP-Ng, whereas N-terminal and C-terminal deletions progressively decreased the ability of GFP- $\mathrm{Ng}$ to show nuclear accumulation.

\section{Cytoplasmic CaM regulates $\mathrm{Ng}$ nuclear translocation in hippocampal neurons}

Cultured hippocampal neurons express very small amounts of $\mathrm{Ng} \mathrm{[46]} \mathrm{and} \mathrm{this} \mathrm{precludes} \mathrm{its} \mathrm{localization}$ by IF. Thus, hippocampal neurons were transfected at DIV7 and analyzed at DIV15-18, a stage where neuronal maturation is mostly completed [47]. As previously noticed in the immunocytochemical study, the nuclear localization of GFP-Ng varied markedly among neighbouring neurons. Further, by simple visual inspection we noticed that GFP-Ng-133Q and GFP-Ng-S36D showed strong nuclear localization, whereas nuclear concentration of GFP-Ng-S36A was low. In view of such heterogeneity and to establish a quantitative comparison among mutants, we decided to categorize neurons into three groups defined on the basis of their relative fluorescence intensity in the nucleus and cytoplasm: i) the $N u c>C y t o$ group, showing a clear nuclear accumulation, ii) the $N u c<C y t o$ group, with less fluorescence

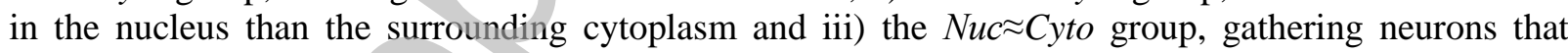
could not be clearly assigned to the other two groups (Figure 5, top panel). Consistent with our previous impression, we found that $23.81 \pm 2.07 \%$ of GFP-Ng neurons fell into the Nuc $>$ Cyto group, and that this figure dropped to $10.02 \pm 3.25$ for GFP-Ng-S36A and ascended to $81.70 \pm 1.99$ and $88.50 \pm 2.42$ for GFP$\mathrm{Ng}-\mathrm{S} 36 \mathrm{D}$ and GFP-Ng-I33Q, respectively. Further, 33.73 $\pm 3.35 \%$ of the GFP-Ng neurons were sorted into the Nuc<Cyto group and this figure rose to $61.59 \pm 5.12$ for GFP-Ng-S36A and dropped to $2.85 \pm 1.27$ and $1.07 \pm 0.71$ for GFP-Ng-S36D and GFP-Ng-I33Q, respectively (Figure 5, lower panel). Finally, GFP expressing neurons, included as reference, were mostly assigned to the Nuc $\approx$ Cyto group, with values $(68.98 \pm 5.93 \%)$ similar to those obtained for GFP-Ng-IQless $(69.81 \pm 6.10 \%)$. To summarize, $\mathrm{Ng}$ mutants that do not bind CaM, such as Ng-I33Q and Ng-S36D, show strong nuclear accumulation, whereas $\mathrm{Ng}-\mathrm{S} 36 \mathrm{~A}$, whose binding to CaM cannot be inhibited by PKC phosphorylation, shows a weak nuclear localization.

With these premises, we hypothesized that CaM binding to cytoplasmic Ng could mask a putative NLS in the $\mathrm{Ng}$ sequence and diminish its nuclear translocation. In support of this view, we found that when $\mathrm{CaM}$ was overexpressed in $\mathrm{NIH}-3 \mathrm{~T} 3$ cells that also expressed $\mathrm{Ng}$, the levels of $\mathrm{Ng}$ present in purified 
nuclear fractions diminished (Figure 6A). Also, in hippocampal neurons, CaM overexpression significantly reduced the percentage of GFP-Ng and GFP-Ng-S36A neurons in the Nuc>Cyto group, therefore lowering the nuclear accumulation of the $\mathrm{Ng}$ forms that bind $\mathrm{CaM}$ (Figure 6B). However, it did not significantly alter the nuclear localization of the $\mathrm{Ng}$ forms that do not bind CaM, most notably GFP-Ng-I33Q and GFP-Ng-IQless. In other words, CaM overexpression only reduces the nuclear levels of $\mathrm{Ng}$ when it is able to bind $\mathrm{Ng}$. Since $\mathrm{Ng}-\mathrm{CaM}$ interaction is prevented when $\mathrm{Ng}$ is phosphorylated [48], we assayed the effect of PKC stimulation on the nuclear localization of GFP-Ng and mutants. Thus, hippocampal neurons were treated with 12-O-tetradecanoylphorbol-13-acetate (TPA) or bisyndolil-maleimide-I (Bis-I), an activator and an inhibitor, respectively, of PKC activity (Figure 6C). As expected, those mutants that cannot be phosphorylated by PKC (GFP-Ng-S36A and GFP-Ng-S36D) did not alter their nuclear localization levels. Neither neurons expressing GFP-Ng-133Q, which can be phosphorylated by PKC but does not bind CaM, altered its nuclear localization. However, the nuclear localization of GFP-Ng significantly increased when PKC stimulation was coupled to phosphatase inhibition with okadaic acid (OKA), suggesting that inhibition of dephosphorylation after PKC phosphorylation reduces $\mathrm{Ng}-\mathrm{CaM}$ reassociation and leaves more $\mathrm{Ng}$ free to move into the nucleus.

\section{$\mathrm{Ng}$ translocation to neuronal nuclei is stimulated by synaptic activity}

Once the nuclear localization of $\mathrm{Ng}$ had been shown, we wanted to investigate its regulation "in vivo". Using acute hippocampal slices, we found that PKC stimulation promotes a transient nuclear accumulation of $\mathrm{Ng}$ that peaked 15-20 min after the addition of TPA and slowly declined thereafter (Figure 7A). Also, in situations of increased excitatory synaptic activity, such as the incubation with 50 $\mu \mathrm{M}$ bicuculline, higher levels of nuclear accumulation were also observed (Figure 7B). These results suggest that increased intracellular $\mathrm{Ca}^{2+}$ levels and PKC activity elicited by synaptic activity would lead to a decrease in $\mathrm{Ng}-\mathrm{CaM}$ levels and would leave more $\mathrm{Ng}$ free to move into the nucleus. To investigate the role of $\mathrm{Ng}$ phosphorylation in the mechanism of nuclear translocation, we analyzed the specific activity of phosphorylated $\mathrm{Ng}$ in the nucleus and cytoplasm, using a specific phospho-Ser36- $\mathrm{Ng}$ antibody. As expected, $\mathrm{Ng}$ phosphorylation at Ser36 augments after PKC stimulation and this is followed by an increased nuclear accumulation. In addition, phosphatase inhibition by OKA not only led to higher levels of $\mathrm{Ng}$ phosphorylation but also to a further increase of nuclear accumulation (Figure $7 \mathrm{C}$, left panel). However, when the specific activity of $\mathrm{Ng}$ phosphorylation was measured in the nuclear and cytoplasmic fractions, no significant differences were found (Figure $7 \mathrm{C}$, right panel). These data suggest that $\mathrm{Ng}$ phosphorylation "per se" does not signal or is not required for nuclear accumulation. Therefore, since PKC mediated $\mathrm{Ng}$ phosphorylation is followed by nuclear accumulation, we propose that the role of $\mathrm{Ng}$ phosphorylation is to prevent the formation of $\mathrm{Ng}-\mathrm{CaM}$ complexes and, consequently, to increase the pool of free $\mathrm{Ng}$ ready for nuclear translocation. This proposal, as suggested by the results obtained after phosphatase inhibition (Figures $6 \mathrm{C}$ and $7 \mathrm{C}$ ), assumes that $\mathrm{Ng}$ dephosphorylation is very active and that phosphatase activity could play a role both in the magnitude and the duration of $\mathrm{Ng}$ nuclear transients.

Since the evidence suggested that excitatory synaptic activity favours the nuclear translocation of $\mathrm{Ng}$, we investigated this hypothesis in live animals. For that, we treated adult rats with pentylenetetrazole (PTZ), a convulsant that elicits high levels of excitatory synaptic activity in the hippocampus and cerebral cortex [49] and brings about the rapid appearance of generalized seizures. The animals were then sacrificed at several times after injection and the nuclear and cytoplasmic fractions, purified from the cerebral cortex and hippocampus, analyzed by immunoblot. As shown in Figure 7D, the $\mathrm{Ng}$ Nuc/Cyto ratio rapidly increases after PTZ administration in the hippocampus, reaching maximal levels at $30 \mathrm{~min}$ and then declining slowly during a period of 4 hours. In the cerebral cortex (Figure 7E), two peaks of nuclear translocation were found, one at $15 \mathrm{~min}$ and the other at $120 \mathrm{~min}$ after PTZ. These data strongly support the hypothesis that excitatory synaptic activity stimulates Ng nuclear accumulation. 
Neurogranin translocates to neuronal nuclei

\section{DISCUSSION}

In the present study, we have shown that $\mathrm{Ng}$ is present in neuronal nuclei and actively translocates from the cytoplasm in response to excitatory synaptic activity. The nuclear localization of $\mathrm{Ng}$ was not clearly established in the literature. Represa et al. observed occasional nuclear staining in some cerebral cortex pyramidal neurons [23] and Watson et al. reported nucleoplasmic immunolabeling in striatal neurons [28]. However, other studies were not able to detect $\mathrm{Ng}$ in neuronal nuclei $\mathrm{Ng}$ [33, 34]. More recently, the presence of $\mathrm{Ng}$ in a nuclear enriched fraction was described [20]. We think that these discrepancies may be related to the difficulties that we found to immunostain intranuclear $\mathrm{Ng}$. The inability of several $\mathrm{Ng}$ antibodies to recognize intranuclear $\mathrm{Ng}$ was somehow surprising. However, the results obtained after saponin permeabilization or using affinity purified $\mathrm{Ng}$ rhod-Fabs confirmed it. The strong nuclear staining observed for ReAsH-labelled 4Cys-Ng also supported this view, and suggested that "GFPtagging" does not affect $\mathrm{Ng}$ subcellular distribution, therefore promoting GFP-Ng as a faithful reporter of intracellular $\mathrm{Ng}$, as happens with other GFP-tagged proteins.

It is known that nuclear pore complexes allow free diffusion of molecules smaller than $40 \mathrm{kDa}$ [50]. Given its small size, Ng diffusion from the cytoplasm could well account for its nuclear localization. However, as shown here, $\mathrm{Ng}$ is not merely present but substantially concentrated within the nucleus. We have shown that GFP-Ng is 2.5 times more concentrated at the nucleus than GFP, and GFP-dNg even more (3.5 times). Assuming that GFP distributes evenly in the cytoplasm and nucleoplasm, our results indicate the existence of active nuclear import mechanisms, intranuclear retention mechanisms, or both. Indeed, the C-terminal portion of $\mathrm{Ng}$ IQ motif features a positively charged sequence $\left(\mathrm{R}_{43} \mathrm{KKIK}\right)$, which is conserved from birds to humans and could act as a NLS. The low nuclear presence of GFP-Ng-IQless -a mutant that lacks the putative NLS- further supports this view and strongly suggests a role of the IQ motif in $\mathrm{Ng}$ nuclear translocation. Once in the nucleus, $\mathrm{Ng}$ would quickly diffuse back to the cytoplasm due to its small size, unless it interacts to intranuclear components. This view is supported by the lack of effect observed for leptomycin B on nuclear accumulation. A rapid nucleocytoplasmic exchange of $\mathrm{Ng}$ could lead to the appearance of nuclear transients, as described in yeast for several transcription factors [51].

How do neurons regulate $\mathrm{Ng}$ nuclear translocation? We propose that the amount of $\mathrm{Ng}$ effectively transported into the nucleus is regulated by its interaction with cytoplasmic components. $\mathrm{Ng}$ association to membranes [20] or interaction with cytoplasmic CaM could mask its NLS and prevent its nuclear translocation. Similar mechanisms have been described for proteins that shuttle between the cytoplasm and the nucleus [52]. For example, the nuclear localization of RGK proteins is modulated by their interaction with $\mathrm{CaM}$ or 14-3-3 protein [53], in the same way as proposed here for $\mathrm{Ng}$. The evidence obtained in the present study to support this view is summarized as follows. First, neurons with high levels of $\mathrm{Ng}$ display a notorious nuclear accumulation, suggesting that excess of $\mathrm{Ng}$ not retained in the cytoplasm is free for nuclear import. Second, since at least some $\mathrm{Ng}$ could be localized in nuclei due to passive diffusion through the nuclear pores, the finding of neurons with no intranuclear Ng (Figure 3BD) suggests the existence of retention mechanisms in the cytoplasm. Third, $\mathrm{Ng}$ mutants that do not bind $\mathrm{CaM}$, such as $\mathrm{Ng}-\mathrm{S} 36 \mathrm{D}$ and $\mathrm{Ng}-\mathrm{I} 33 \mathrm{Q}$, are highly concentrated in nuclei of hippocampal neurons, whereas, Ng-S36A, whose binding to CaM is not affected by phosphorylation, displays a weak nuclear localization. These results suggest that $\mathrm{Ng}$ binding to cytoplasmic $\mathrm{CaM}$ prevents its nuclear import. The nuclear localization differences observed between hippocampal neurons and NIH-3T3 cells for these mutants are most likely due to the high expression attained shortly after transfection in NIH-3T3 cells, which would saturate and overflow the cytoplasmic retention mechanisms. Fourth, CaM overexpression in neurons and cell lines leads to a reduction of nuclear $\mathrm{Ng}$, consistent with its role as a retention mechanism. Finally, stimulation of $\mathrm{Ng}$ phosphorylation in cultured neurons and acute hippocampal slices, which reduces the levels of CaM-Ng interaction, leads to increased nuclear accumulation of $\mathrm{Ng}$.

Although more data are needed, the present study provides sufficient evidence to suggest that nuclear $\mathrm{Ng}$ has physiological relevance. Nuclear localization of $\mathrm{Ng}$ is developmentally regulated in the rat brain; showing very low levels in the first week of life that increase dramatically during the second and third weeks, a period of intense synaptogenesis. Also, intranuclear $\mathrm{Ng}$ levels are noticeably 
heterogeneous among neighbouring neurons, suggesting a relationship between nuclear accumulation and synaptic activity. Finally, the induction of a generalized increase in excitatory synaptic activity after PTZ administration led to a transient translocation of $\mathrm{Ng}$ to neuronal nuclei in the cerebral cortex and hippocampus. The next question arising is: what is the role of $\mathrm{Ng}$ in the neuronal nucleus? At the moment, we have no data to answer that question. Detailed intranuclear localization studies are needed to reveal specific association of $\mathrm{Ng}$ with intranuclear components. So far, $\mathrm{Ng}$ functionality has been related to $\mathrm{Ca}^{2+} / \mathrm{CaM}$ signal transduction $[25,54]$, and there are several $\mathrm{Ca}^{2+} / \mathrm{CaM}$ regulated processes within neuronal nuclei that affect long term synaptic plasticity. Nuclear $\mathrm{CaM}$ is needed for activityinduced phosphorylation of CREB (cAMP response element-binding protein) and the expression of activity-induced genes [55]. A candidate to transduce nuclear $\mathrm{Ca} 2+/ \mathrm{CaM}$ signalling in long term plasticity is CaMK-IV [56]. On the other hand, phosphatidic acid is a prominent product of endogenous neuronal nuclear lipid phosphorylation [57], probably generated by nuclear diacylglycerol kinases [58]. Since Ng binds to phosphatidic acid [20], Ng could have a role in intranuclear PA signalling.

\section{ACKNOWLEDGEMENTS}

This work was supported by a grant from the Spanish Ministry of Science and Technology (BFI200201581). We thank "Fundación Ramón Areces" for institutional support. We thank Ms Beatriz Domingo and Dr Juan Llopis for their collaboration in the ReAsH labelling experiments. We thank Dr Noa Beatriz Martín-Cófreces for helpful revision of the manuscript. 
Neurogranin translocates to neuronal nuclei

\section{REFERENCES}

1 Kelleher, R. J., 3rd, Govindarajan, A. and Tonegawa, S. (2004) Translational regulatory mechanisms in persistent forms of synaptic plasticity. Neuron. 44, 59-73

2 Greer, P. L. and Greenberg, M. E. (2008) From synapse to nucleus: calcium-dependent gene transcription in the control of synapse development and function. Neuron. 59, 846-860

3 Bourtchuladze, R., Frenguelli, B., Blendy, J., Cioffi, D., Schutz, G. and Silva, A. J. (1994) Deficient long-term memory in mice with a targeted mutation of the cAMP-responsive element-binding protein. Cell. 79, 59-68

4 Silva, A. J., Paylor, R., Wehner, J. M. and Tonegawa, S. (1992) Impaired spatial learning in alpha-calciumcalmodulin kinase II mutant mice. Science. 257, 206-211

5 Kelleher, R. J., 3rd, Govindarajan, A., Jung, H. Y., Kang, H. and Tonegawa, S. (2004) Translational control by MAPK signaling in long-term synaptic plasticity and memory. Cell. 116, 467-479

6 Wellmann, H., Kaltschmidt, B. and Kaltschmidt, C. (2001) Retrograde transport of transcription factor NFkappa B in living neurons. J Biol Chem. 276, 11821-11829

7 Graef, I. A., Mermelstein, P. G., Stankunas, K., Neilson, J. R., Deisseroth, K., Tsien, R. W. and Crabtree, G. R. (1999) L-type calcium channels and GSK-3 regulate the activity of NF-ATc4 in hippocampal neurons. Nature. 401, 703-708

8 Hardingham, G. E., Arnold, F. J. and Bading, H. (2001) A calcium microdomain near NMDA receptors: on switch for ERK-dependent synapse-to-nucleus communication. Nat Neurosci. 4, 565-566

9 Faure, C., Corvol, J. C., Toutant, M., Valjent, E., Hvalby, O., Jensen, V., El Messari, S., Corsi, J. M., Kadare, G. and Girault, J. A. (2007) Calcineurin is essential for depolarization-induced nuclear translocation and tyrosine phosphorylation of PYK2 in neurons. J Cell Sci, 120, 3034-3044

10 Chawla, S., Vanhoutte, P., Arnold, F. J., Huang, C. L. and Bading, H. (2003) Neuronal activity-dependent nucleocytoplasmic shuttling of HDAC4 and HDAC5. J Neurochem. 85, 151-159

11 Deisseroth, K., Heist, E. K. and Tsien, R. W. (1998) Translocation of calmodulin to the nucleus supports CREB phosphorylation in hippocampal neurons. Nature. 392, 198-202

12 Jordan, B. A., Fernholz, B. D., Khatri, L. and Ziff, E. B. (2007) Activity-dependent AIDA-1 nuclear signaling regulates nucleolar numbers and protein synthesis in neurons. Nat Neurosci. 10, 427-435

13 Birbach, A., Verkuyl, J. M. and Matus, A. (2006) Reversible, activity-dependent targeting of profilin to neuronal nuclei. Exp Cell Res. 312, 2279-2287

14 Kim, Y. W., Kim, Y., Kim, E. H., Koh, D., Sun, W. and Kim, H. (2008) Expression and subcellular localization of thymosin beta 15 following kainic acid treatment in rat brain. Biochem Biophys Res Commun. 371, 664-669

15 Dieterich, D. C., Karpova, A., Mikhaylova, M., Zdobnova, I., Konig, I., Landwehr, M., Kreutz, M., Smalla, K. H., Richter, K., Landgraf, P., Reissner, C., Boeckers, T. M., Zuschratter, W., Spilker, C., Seidenbecher, C. I., Garner, C. C., Gundelfinger, E. D. and Kreutz, M. R. (2008) Caldendrin-Jacob: a protein liaison that couples NMDA receptor signalling to the nucleus. PLoS Biol. 6, e34

16 Baudier, J., Deloulme, J. C., Van Dorsselaer, A., Black, D. and Matthes, H. W. (1991) Purification and characterization of a brain-specific protein kinase $\mathrm{C}$ substrate, neurogranin (p17). Identification of a consensus amino acid sequence between neurogranin and neuromodulin (GAP43) that corresponds to the protein kinase $\mathrm{C}$ phosphorylation site and the calmodulin-binding domain. J Biol Chem. 266, 229-237 
17 Watson, J. B., Battenberg, E. F., Wong, K. K., Bloom, F. E. and Sutcliffe, J. G. (1990) Subtractive cDNA cloning of RC3, a rodent cortex-enriched mRNA encoding a novel 78 residue protein. J Neurosci Res. 26, 397 408

18 Baudier, J., Bronner, C., Kligman, D. and Cole, R. D. (1989) Protein kinase C substrates from bovine brain. Purification and characterization of neuromodulin, a neuron-specific calmodulin-binding protein. J. Biol. Chem. 264, 1824-1828

19 Gerendasy, D. D., Herron, S. R., Watson, J. B. and Sutcliffe, J. G. (1994) Mutational and biophysical studies suggest RC3/neurogranin regulates calmodulin availability. J Biol Chem. 269, 22420-22426

20 Dominguez-Gonzalez, I., Vazquez-Cuesta, S. N., Algaba, A. and Diez-Guerra, F. J. (2007) Neurogranin binds to phosphatidic acid and associates to cellular membranes. Biochem J. 404, 31-43

21 Gerendasy, D. D., Herron, S. R., Jennings, P. A. and Sutcliffe, J. G. (1995) Calmodulin stabilizes an amphiphilic alpha-helix within $\mathrm{RC} 3 /$ neurogranin and GAP-43/neuromodulin only when $\mathrm{Ca} 2+$ is absent. J Biol Chem. 270, 6741-6750

22 Alvarez-Bolado, G., Rodriguez-Sanchez, P., Tejero-Diez, P., Fairen, A. and Diez-Guerra, F. J. (1996) Neurogranin in the development of the rat telencephalon. Neuroscience. $73,565-580$

23 Represa, A., Deloulme, J. C., Sensenbrenner, M., Ben-Ari, Y. and Baudier, J. (1990) Neurogranin: immunocytochemical localization of a brain-specific protein kinase C substrate. J Neurosci. 10, 3782-3792

24 Clayton, D. F., George, J. M., Mello, C. V. and Siepka, S. M. (2009) Conservation and expression of IQdomain-containing calpacitin gene products (neuromodulin/GAP-43, neurogranin/RC3) in the adult and developing oscine song control system. Dev Neurobiol. 69, 124-140

25 Huang, K. P., Huang, F. L., Jager, T., Li, J., Reymann, K. G. and Balschun, D. (2004) Neurogranin/RC3 enhances long-term potentiation and learning by promoting calcium-mediated signaling. J. Neurosci. 24, 10660-10669

26 Pak, J. H., Huang, F. L., Li, J., Balschun, D., Reymann, K. G., Chiang, C., Westphal, H. and Huang, K. P. (2000) Involvement of neurogranin in the modulation of calcium/calmodulin-dependent protein kinase II, synaptic plasticity, and spatial learning: a study with knockout mice. Proc Natl Acad Sci U S A. 97, 1123211237

27 Krucker, T., Siggins, G. R., McNamara, R. K., Lindsley, K. A., Dao, A., Allison, D. W., De Lecea, L., Lovenberg, T. W., Sutcliffe, J. G. and Gerendasy, D. D. (2002) Targeted disruption of RC3 reveals a calmodulin-based mechanism for regulating metaplasticity in the hippocampus. J Neurosci. 22, 5525-5535

28 Watson, J. B., Sutcliffe, J. G. and Fisher, R. S. (1992) Localization of the protein kinase C phosphorylation/calmodulin-binding substrate RC3 in dendritic spines of neostriatal neurons. Proc Natl Acad Sci U S A. 89, 8581-8585

29 Chang, J. W., Schumacher, E., Coulter, P. M., 2nd, Vinters, H. V. and Watson, J. B. (1997) Dendritic translocation of RC3/neurogranin mRNA in normal aging, Alzheimer disease and fronto-temporal dementia. J. Neuropathol. Exp. Neurol. 56, 1105-1118

30 Mori, Y., Imaizumi, K., Katayama, T., Yoneda, T. and Tohyama, M. (2000) Two cis-acting elements in the 3 untranslated region of alpha-CaMKII regulate its dendritic targeting. Nat. Neurosci. 3, 1079-1084

31 Pinkstaff, J. K., Chappell, S. A., Mauro, V. P., Edelman, G. M. and Krushel, L. A. (2001) Internal initiation of translation of five dendritically localized neuronal mRNAs. Proc Natl Acad Sci U S A. 98, 2770-2775

32 Krueger, D. D. and Nairn, A. C. (2007) Expression of PKC substrate proteins, GAP-43 and neurogranin, is downregulated by cAMP signaling and alterations in synaptic activity. Eur J Neurosci. 26, 3043-3053 
33 Watson, J. B., Szijan, I. and Coulter, P. M., 2nd. (1994) Localization of RC3 (neurogranin) in rat brain subcellular fractions. Brain Res Mol Brain Res. 27, 323-328

34 Neuner-Jehle, M., Denizot, J. P. and Mallet, J. (1996) Neurogranin is locally concentrated in rat cortical and hippocampal neurons. Brain Res. 733, 149-154

35 Andrew, S. M. and Titus, J. A. (2001) Fragmentation of immunoglobulin G. Curr Protoc Immunol. Chapter 2, Unit 28

36 Martin, B. R., Giepmans, B. N., Adams, S. R. and Tsien, R. Y. (2005) Mammalian cell-based optimization of the biarsenical-binding tetracysteine motif for improved fluorescence and affinity. Nat Biotechnol. 23, 13081314

37 Kremers, G. J., Goedhart, J., van den Heuvel, D. J., Gerritsen, H. C. and Gadella, T. W., Jr. (2007) Improved green and blue fluorescent proteins for expression in bacteria and mammalian cells. Biochemistry. 46, 37753783

38 DeFelipe, J. and Fairen, A. (1993) A simple and reliable method for correlative light and electron microscopic studies. J Histochem Cytochem. 41, 769-772

39 Adams, S. R. and Tsien, R. Y. (2008) Preparation of the membrane-permeant biarsenicals FlAsH-EDT2 and ReAsH-EDT2 for fluorescent labeling of tetracysteine-tagged proteins. Nat Protoc. 3, 1527-1534

40 Domingo, B., Sabariegos, R., Picazo, F. and Llopis, J. (2007) Imaging FRET standards by steady-state fluorescence and lifetime methods. Microsc Res Tech. 70, 1010-1021

41 Kaech, S. and Banker, G. (2006) Culturing hippocampal neurons. Nat Protoc. 1, 2406-2415

42 Tejero-Diez, P., Rodriguez-Sanchez, P. and Diez-Guerra, F. J. (1999) Microscale purification of proteins exhibiting anomalous electrophoretic migration: application to the analysis of GAP-43 phosphorylation. Anal Biochem. 274, 278-282

43 Graham, J. M. (2001) Isolation of nuclei and nuclear membranes from animal tissues. Curr Protoc Cell Biol. Chapter 3, Unit 310

44 McIntyre, D. C. and Racine, R. J. (1986) Kindling mechanisms: current progress on an experimental epilepsy model. Prog Neurobiol. 27, 1-12

45 Lusk, C. P., Blobel, G. and King, M. C. (2007) Highway to the inner nuclear membrane: rules for the road. Nat Rev Mol Cell Biol. 8, 414-420

46 Rodriguez-Sanchez, P., Tejero-Diez, P. and Diez-Guerra, F. J. (1997) Glutamate stimulates neurogranin phosphorylation in cultured rat hippocampal neurons. Neurosci Lett. 221, 137-140

47 Dotti, C. G., Sullivan, C. A. and Banker, G. A. (1988) The establishment of polarity by hippocampal neurons in culture. J Neurosci. 8, 1454-1468

48 Huang, K. P., Huang, F. L. and Chen, H. C. (1993) Characterization of a 7.5-kDa protein kinase C substrate (RC3 protein, neurogranin) from rat brain. Arch Biochem Biophys. 305, 570-580

49 Stringer, J. L. (1994) Pentylenetetrazol elicits epileptiform activity in the dentate gyrus of the urethane anesthetized rat by activation of the entorhinal cortex. Brain Res. 636, 221-226

50 Terry, L. J., Shows, E. B. and Wente, S. R. (2007) Crossing the nuclear envelope: hierarchical regulation of nucleocytoplasmic transport. Science. 318, 1412-1416 
51 Cai, L., Dalal, C. K. and Elowitz, M. B. (2008) Frequency-modulated nuclear localization bursts coordinate gene regulation. Nature. 455, 485-490

52 Blank, V., Kourilsky, P. and Israel, A. (1991) Cytoplasmic retention, DNA binding and processing of the NFkappa B p50 precursor are controlled by a small region in its C-terminus. EMBO J. 10, 4159-4167

53 Mahalakshmi, R. N., Nagashima, K., Ng, M. Y., Inagaki, N., Hunziker, W. and Beguin, P. (2007) Nuclear transport of Kir/Gem requires specific signals and importin alpha5 and is regulated by calmodulin and predicted serine phosphorylations. Traffic. 8, 1150-1163

$54 \mathrm{Wu}$, J., Huang, K. P. and Huang, F. L. (2003) Participation of NMDA-mediated phosphorylation and oxidation of neurogranin in the regulation of $\mathrm{Ca} 2+-$ and $\mathrm{Ca} 2+$ /calmodulin-dependent neuronal signaling in the hippocampus. J Neurochem. 86, 1524-1533

55 Limback-Stokin, K., Korzus, E., Nagaoka-Yasuda, R. and Mayford, M. (2004) Nuclear calcium/calmodulin regulates memory consolidation. J Neurosci. 24, 10858-10867

56 Wayman, G. A., Lee, Y. S., Tokumitsu, H., Silva, A. and Soderling, T. R. (2008) Calmodulin-kinases: modulators of neuronal development and plasticity. Neuron. 59, 914-931

57 Baker, R. R. and Chang, H. (2001) Phosphatidic acid is the prominent product of endogenous neuronal nuclear lipid phosphorylation, an activity enhanced by sphingosine, linked to phospholipase $\mathrm{C}$ and associated with the nuclear envelope. Biochim Biophys Acta. 1534, 110-120

58 Raben, D. M. and Tu-Sekine, B. (2008) Nuclear diacylglycerol kinases: regulation and roles. Front Biosci. 13, 590-597 
Neurogranin translocates to neuronal nuclei

\section{FIGURE LEGENDS}

\section{Figure 1.- Nuclear localization of GFP-Ng.}

NIH-3T3 cells expressing GFP-Ng (A) or Ng (B) were processed for "normal IF", "long IF" or "sap + long IF" as described in the experimental and results sections. Images of GFP fluorescence (GFP, A) and indirect IF, using $\mathrm{Ng}$ (Ab756 1:5.000) and Alexa555-conjugated antibodies (1:2.000) (anti-Ng, A and $\mathrm{B}$ ) are shown. Colour merged images (merge) and the colour scatter plots and Pearson's correlation coefficients obtained for the colocalization analysis are also included (A). Under "normal IF" conditions no intranuclear GFP-Ng or Ng could be detected by $\mathrm{Ng}$ antibodies, although the fluorescence of GFP clearly indicates nuclear localization. Using "long IF" or "sap + long IF", $\mathrm{Ng}$ antibodies revealed the presence of GFP-Ng or Ng in the nucleus, indicating that both are present in nuclei. (C) Hela cells expressing 4Cys- $\mathrm{Ng}$ were labelled with ReAsH and processed for "normal IF" with $\mathrm{Ng}$ antibodies. ReAsH-labelled 4Cys-Ng displays a strong nuclear localization that is not observed by indirect IF (anti-Ng) and gives rise to low levels of colocalization. (D) NIH-3T3 cells expressing GFP$\mathrm{Ng}$ were processed for "long IF" using affinity-purified rhodamine-labelled Ng Fabs (1:50). Both GFPderived fluorescence (green) and indirect IF (red) images indicated a clear nuclear localization of GFP$\mathrm{Ng}$, further confirmed by a very good colocalization $($ bar $=25 \mu \mathrm{m})$.

Figure 2.- Nuclear localization of $\mathrm{Ng}$ in several brain regions during postnatal development.

Rats (Wistar strain) were sacrificed at several postnatal ages and the striatum, hippocampus and cerebral cortex quickly dissected, weighed and processed to separate the nuclear (Nuc) and cytoplasmic (Cyto) fractions, which were analyzed by immunoblot. The histogram represents the ratios between $\mathrm{Ng}$ present in the nuclear and the cytoplasmic fractions (means \pm S.E.M.; $n=4$ ). Typical immunoblots are shown. Note that, in all regions, $\mathrm{Ng}$ was practically absent from cell nuclei during the first week of life and increased substantially during the second and third weeks.

Figure 3.- Immunocytochemical localization of $\mathrm{Ng}$ in the rat brain.

Adult rats were processed for $\mathrm{Ng}$ immunocytochemistry using the affinity-purified antibody Ab205 and analyzed with the optical $(\mathrm{A}-\mathrm{E})(\mathrm{bar}=50 \mu \mathrm{m})$ or the electron microscope $(\mathrm{F}-\mathrm{G})(\mathrm{bar}=5 \mu \mathrm{m})$, as thick $(50 \mu \mathrm{m}, \mathrm{A}$ and $\mathrm{E})$, semithin $(1 \mu \mathrm{m}, \mathrm{B}-\mathrm{D})$ ) and ultrathin $(80 \mathrm{~nm}, \mathrm{~F}-\mathrm{G})$ sections from cerebral cortex (B-D) or hippocampus (E-G). (A) Dorsal region of a coronal section showing strong $\mathrm{Ng}$ immunostaining in layers II-IV of the cerebral cortex (left box) and in the granular and pyramidal cells (right box) of the hippocampus. (B-D) Note the differences of nuclear localization among neighbouring neurons in several cerebral cortex areas. (E) CA2 region showing neurons with nuclear immunostaining. The insert shows a region rich in neurons with prominent intranuclear staining. (F,G) CA2 neurons showing low or high nuclear immunostaining, viewed by EM. Cytoplasmic and nuclear regions are outlined in yellow and cyan, respectively.

Figure 4.- Nuclear localization of $\mathrm{Ng}$ depends on its $\mathrm{IQ}$ motif.

NIH-3T3 cells expressing GFP, GFP-Ng or other GFP-Ng mutants were fixed and counterstained with To-Pro3 to visualize cell nuclei. (A) Image sequence illustrating the procedure to select the areas corresponding to the nucleus (yellow) and cytoplasm (cyan) (see also the experimental section). (B) Scheme showing the sequence of rat $\mathrm{Ng}$ and the different mutants used in the study. The sequence corresponding to the IQ motif is coloured in green (C) Histogram showing the Nuc/Cyto intensity ratios calculated for each group of cells. The ratio obtained for GFP expressing cells was used to normalize the ratios of the other groups. More than 30 cells, in three separate experiments, were imaged and processed in each group. To calculate statistical significant differences, GFP-Ng data were used as reference.

Figure 5.- Distinct nuclear localization of $\mathrm{Ng}$ mutants in hippocampal neurons.

Hippocampal neurons were transfected with GFP, GFP-Ng or several other GFP-Ng mutants, fixed between DIV15 and DIV18 and labelled with To-Pro3. The upper panel shows typical confocal microscopy images of neurons with low (Nuc<Cyto, GFP-Ng-S36A), high (Nuc>Cyto, GFP-Ng-I33Q) or intermediate $(\mathrm{Nuc} \approx \mathrm{Cyto}, \mathrm{GFP})$ levels of nuclear fluorescence. Below, the histogram shows the data obtained after sorting more than 400 neurons from at least three independent experiments, into the three 
Neurogranin translocates to neuronal nuclei

groups. Note that GFP-Ng-S36A neurons show less fluorescence in the nucleus, whereas GFP-NgS36D and GFP-Ng-I33Q neurons show more intranuclear fluorescence. GFP-Ng data were used as reference to display statistical significance between Nuc>Cyto subgroups.

\section{Figure 6.- CaM regulates $\mathrm{Ng}$ nuclear translocation}

(A) NIH-3T3 cells in P35 plates were transfected with $0.4 \mu \mathrm{g}$ pcDNA3-Ng $+1,6 \mu \mathrm{g}$ pcDNA3 (-CaM) or $0.4 \mu \mathrm{g}$ pcDNA3-Ng $+1,6 \mu \mathrm{g}$ pcDNA3-CaM $(+\mathrm{CaM})$ and, 24 hours later, the nuclear and cytoplasmic fractions separated and analyzed by immunoblot. Note that $\mathrm{Ng}$ content is reduced in the nuclear fraction of cells overexpressing CaM. (B) Hippocampal neurons transfected with $0.2 \mu \mathrm{g}$ of GFP, GFP-Ng or other GFP-Ng mutants and either $0.8 \mu \mathrm{g}$ of pcDNA3 $(-\mathrm{CaM})$ or $0.8 \mu \mathrm{g}$ of pcDNA3-CaM $(+\mathrm{CaM})$ were analyzed at DIV15-18 and sorted into the three groups. Note that CaM overexpression only affected the nuclear localization of neurons expressing GFP-Ng or GFP-Ng-S36A. Statistical significance shows the effect of CaM overexpression. (C) Hippocampal neurons transfected as above were incubated during 20 min with $200 \mathrm{nM}$ 12-O-tetradecanoylphorbol-13-acetate (TPA), $0.5 \mu \mathrm{M}$ okadaic acid (OKA), $1 \mu \mathrm{M}$ bisyndolil-maleimide-I (Bis-I) or a combination of TPA and OKA, and analyzed at DIV15-18. Note that the nuclear localization of GFP-Ng significantly increases when TPA and OKA were combined. No changes of nuclear localization were observed in neurons expressing mutants that cannot be phosphorylated (GFP-Ng-S36A and GFP-Ng-S36D) or that do not bind CaM (GFP-Ng-S36D and GFP$\mathrm{Ng}-\mathrm{I} 33 \mathrm{Q})$, as expected.

\section{Figure 7.- Ng nuclear translocation is regulated by synaptic activity}

(A) Acute hippocampal slices from adult rats were treated with, homogenized at different times of incubation and their nuclear and cytoplasmic fractions separated and analyzed by immunoblot. $\mathrm{Ng}$ content was quantified in the blots and the Nuc/Cyto ratios obtained plotted versus time. Note that a 1520 min treatment with TPA increased more than 50\% the Nuc/Cyto ratio. (B) Acute hippocampal slices from adult rats were treated with $50 \mu \mathrm{M}$ bicuculline, $100 \mu \mathrm{M}$ l-glutamate or $200 \mathrm{nM}$ TPA (as positive control) during $15 \mathrm{~min}$ and the $\mathrm{Ng}$ Nuc/Cyto ratios obtained as described above. Note that the excitatory synaptic activity increase elicited by bicuculline led to a significantly greater nuclear localization of $\mathrm{Ng}$. (C) Acute hippocampal slices from adult rats were treated during 15 min with $200 \mathrm{nM}$ TPA, $0.5 \mu \mathrm{M}$ OKA or a combination of TPA and OKA, their nuclear and cytoplasmic fractions obtained and analyzed by immunoblot with $\mathrm{Ng}$ (anti-Ng) and phospho-Ser36-Ng (anti-P-Ng) specific antibodies. The left panel shows a typical immunoblot set. Note that OKA and TPA (OKA+TPA) clearly increased the amount of $\mathrm{Ng}$ in the nuclear fraction, even when compared with TPA treated slices. The histogram at the right panel shows the specific activity of $\mathrm{Ng}$ phosphorylation at Ser36 obtained for the nuclear and cytoplasmic fractions with the different treatments. No significant differences of specific activity were observed when nuclear and cytoplasmic fractions were compared. (D, E) Adult rats were treated with PTZ (45 mg/ Kg, i.p.), sacrificed at several times after injection, their brains quickly removed and the hippocampus (D) and cerebral cortex (E) dissected, weighed and processed to separate the nuclear and cytoplasmic fractions. $\mathrm{Ng}$ content in each fraction was quantified by immunoblot and the Nuc/Cyto ratios obtained plotted versus time. Statistically significant increases in the $\mathrm{Ng}$ Nuc/Cyto ratio could be detected between 15 and 30 min after PTZ in the hippocampus. Data are means \pm SD $(n=4)$. 


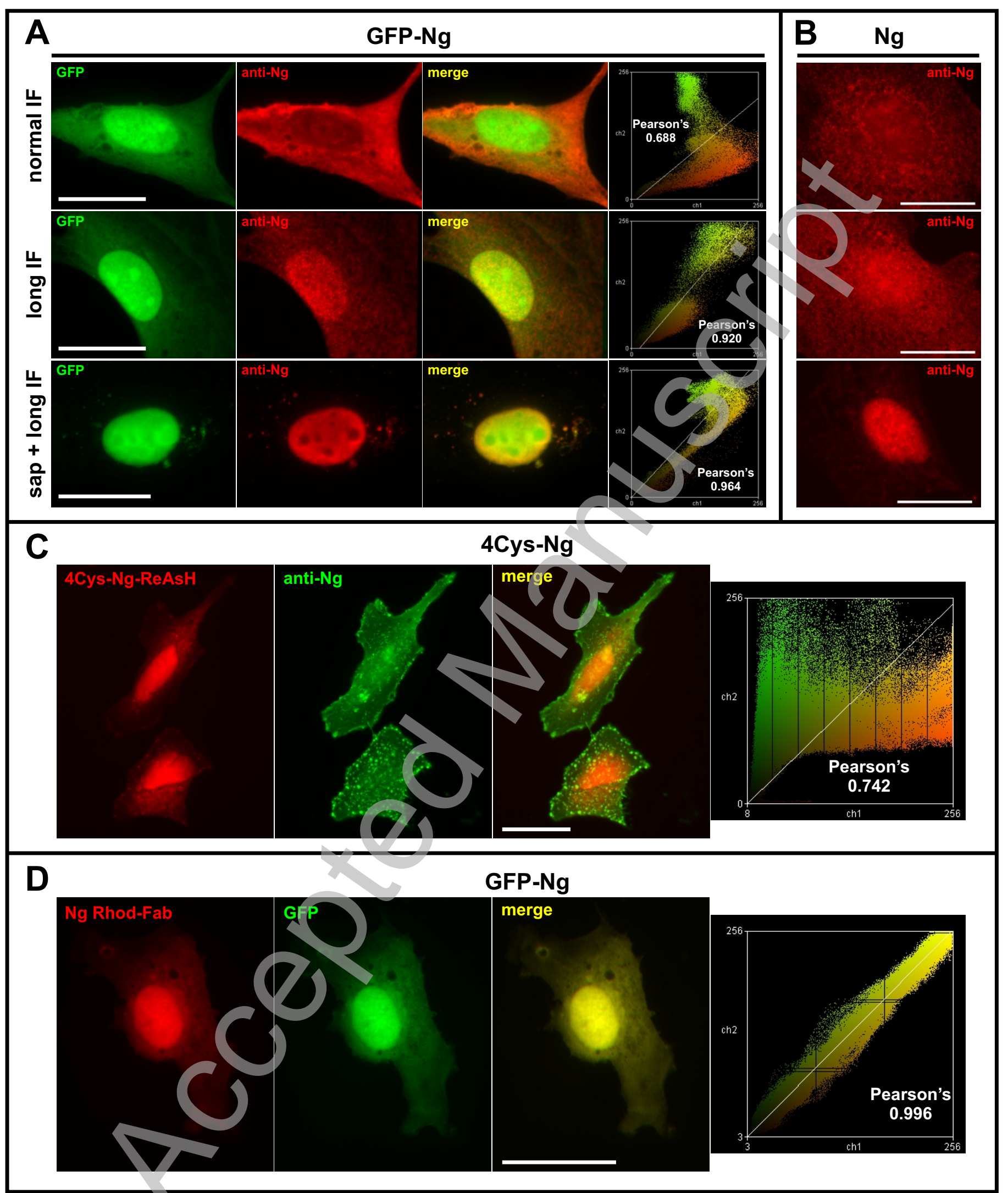

Figure 1

Licenced copy. Copying is not permitted, except with prior permission and as allowed by law. (C) 2009 The Authors Journal compilation (c) 2009 Portland Press Limited 


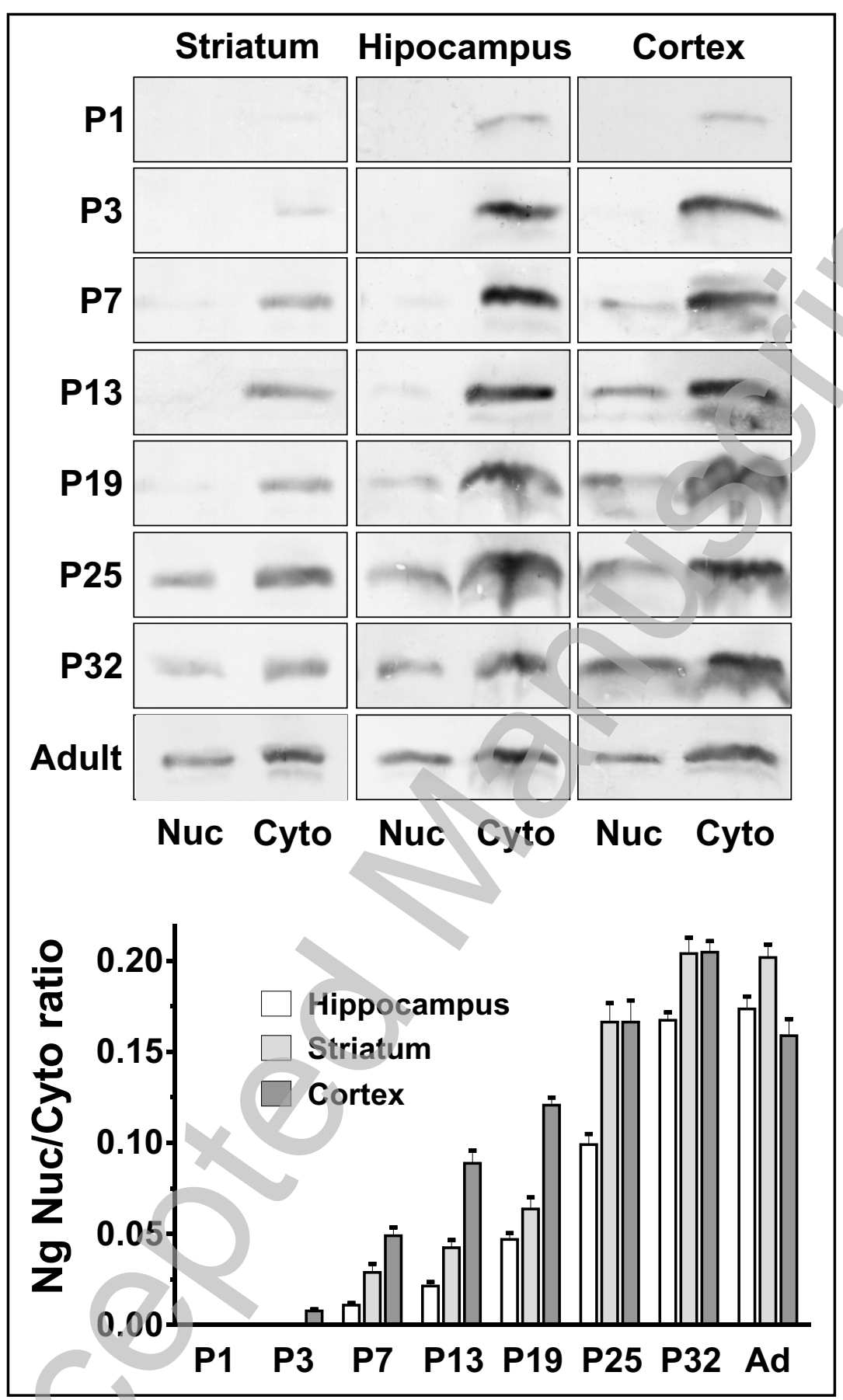

Figure 2 


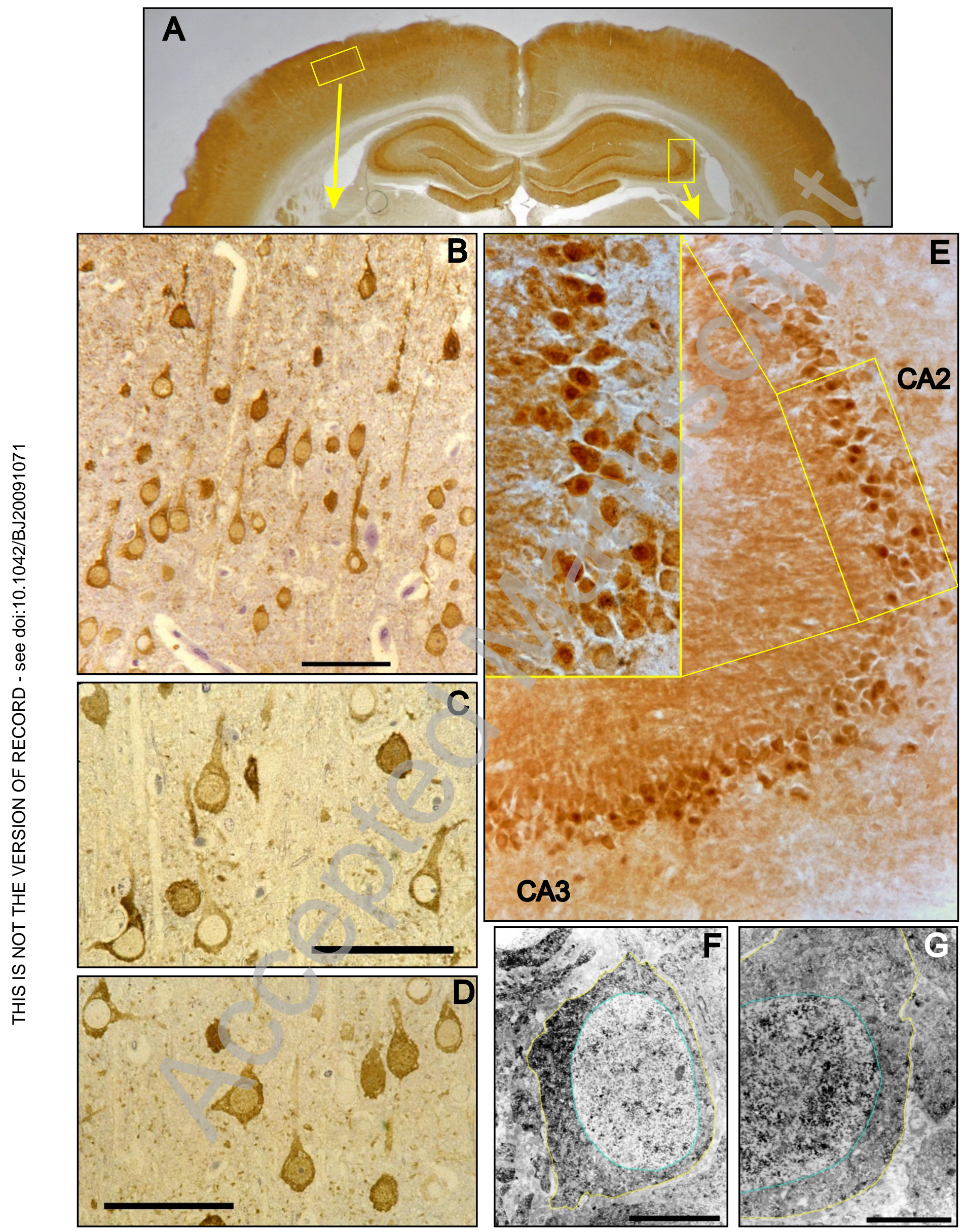

Figure 3

Licenced copy. Copying is not permitted, except with prior permission and as allowed by law. (C) 2009 The Authors Journal compilation (c) 2009 Portland Press Limited 


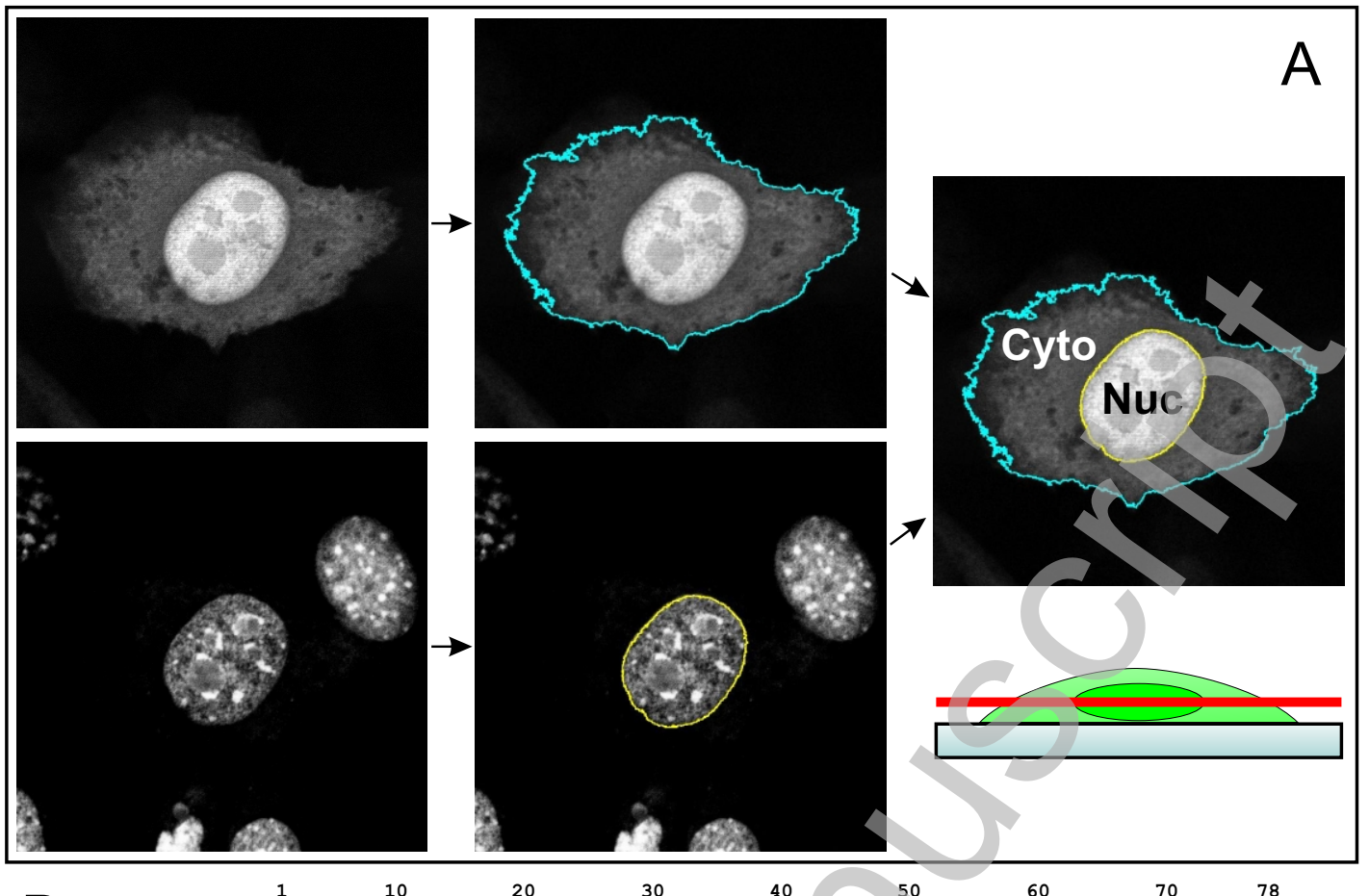

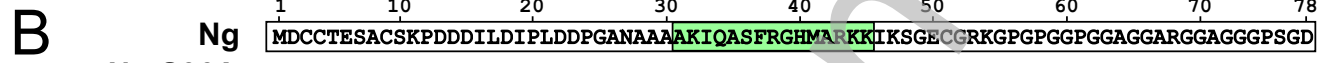

Ng-S36A

$\mathrm{Ng}-\mathrm{S} 36 \mathrm{D}$

$\mathrm{Ng}-133 \mathrm{Q}$

$\mathrm{Ng}-\mathrm{C} 3,4,9 \mathrm{~S}$

Ng-IQless

$\mathrm{Ng}$ 1-70

$\mathrm{Ng} 1-60$

$\mathrm{Ng} 1-50$

$\mathrm{Ng} \mathrm{30-78}$

Ng 52-78

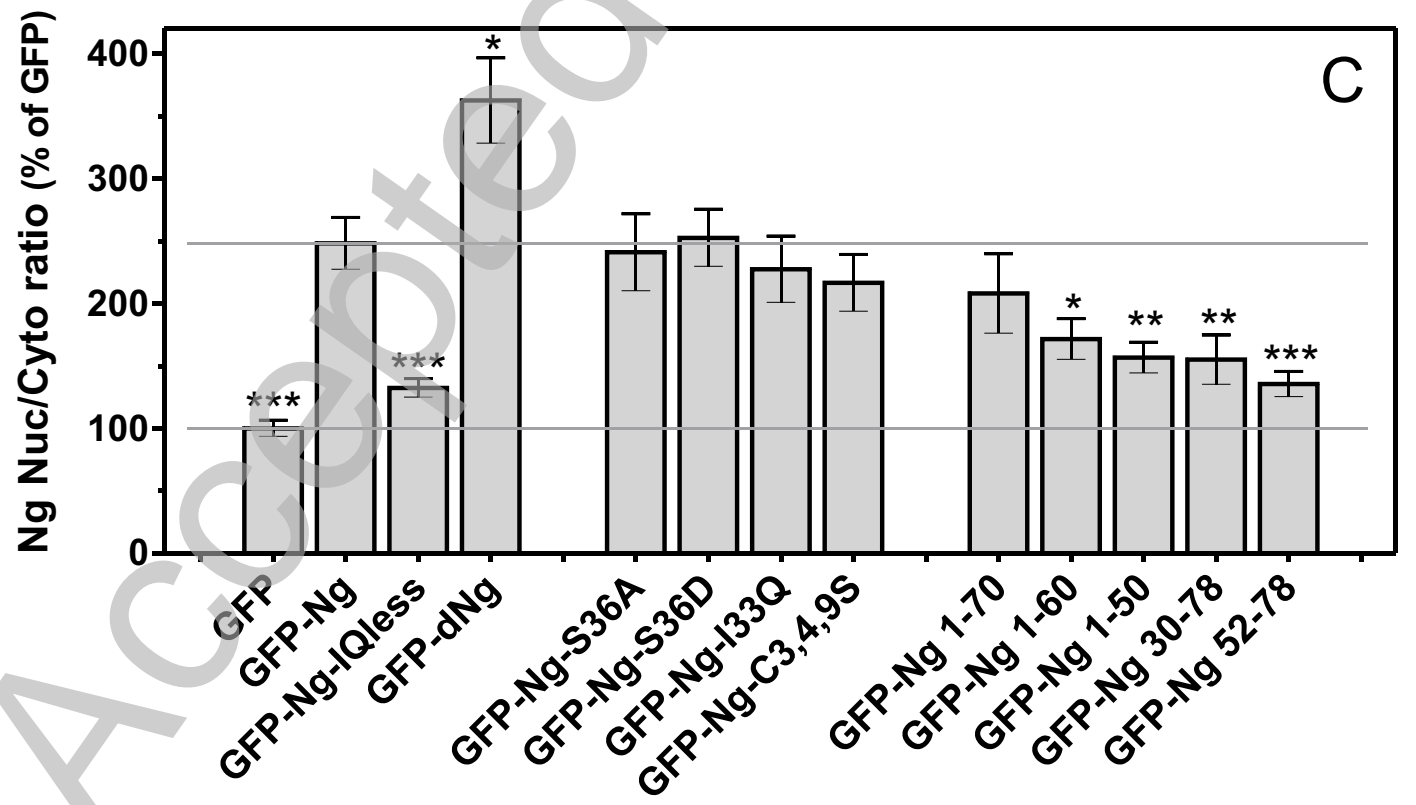

Figure 4

Licenced copy. Copying is not permitted, except with prior permission and as allowed by law.

(C) 2009 The Authors Journal compilation (c) 2009 Portland Press Limited 


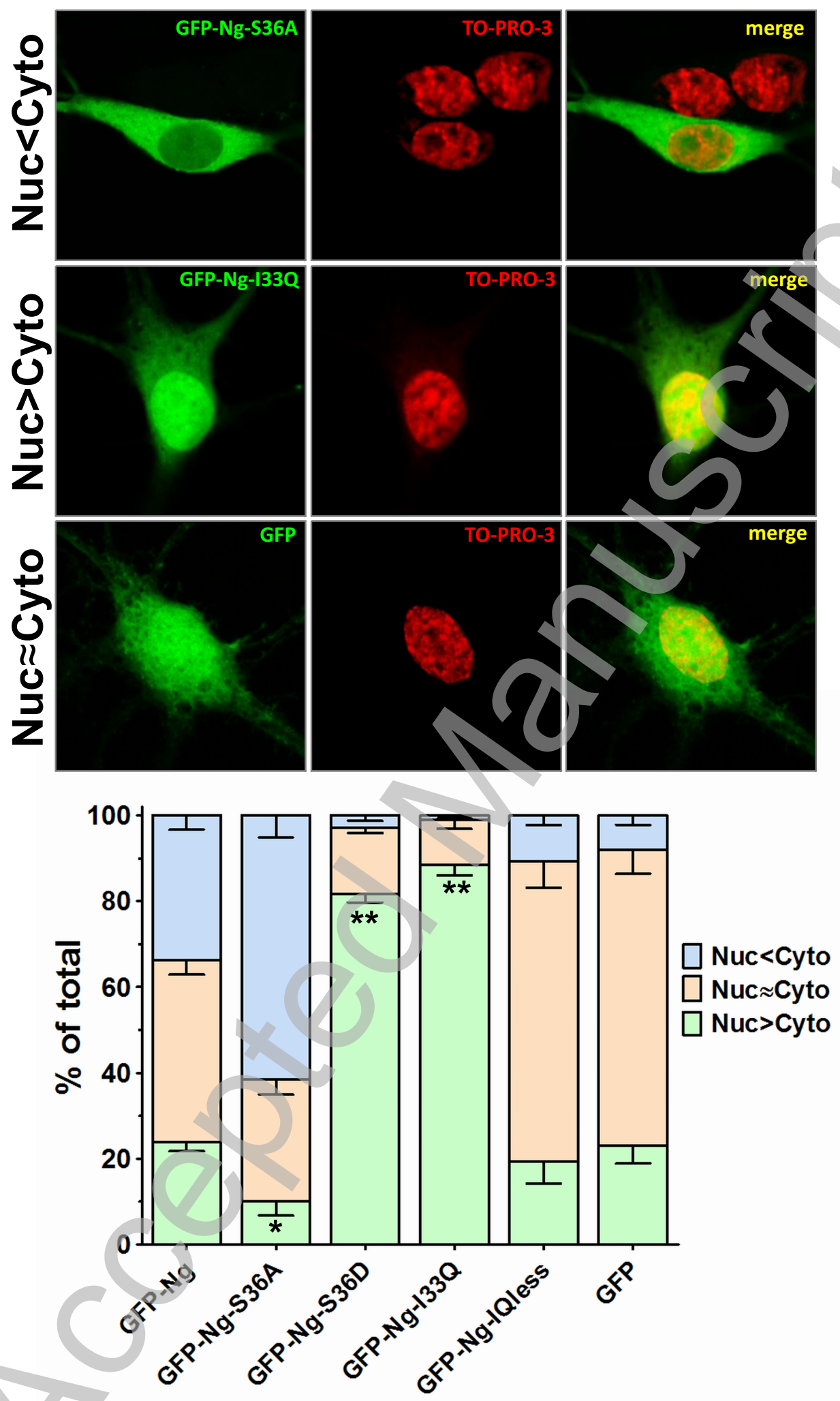

Figure 5 


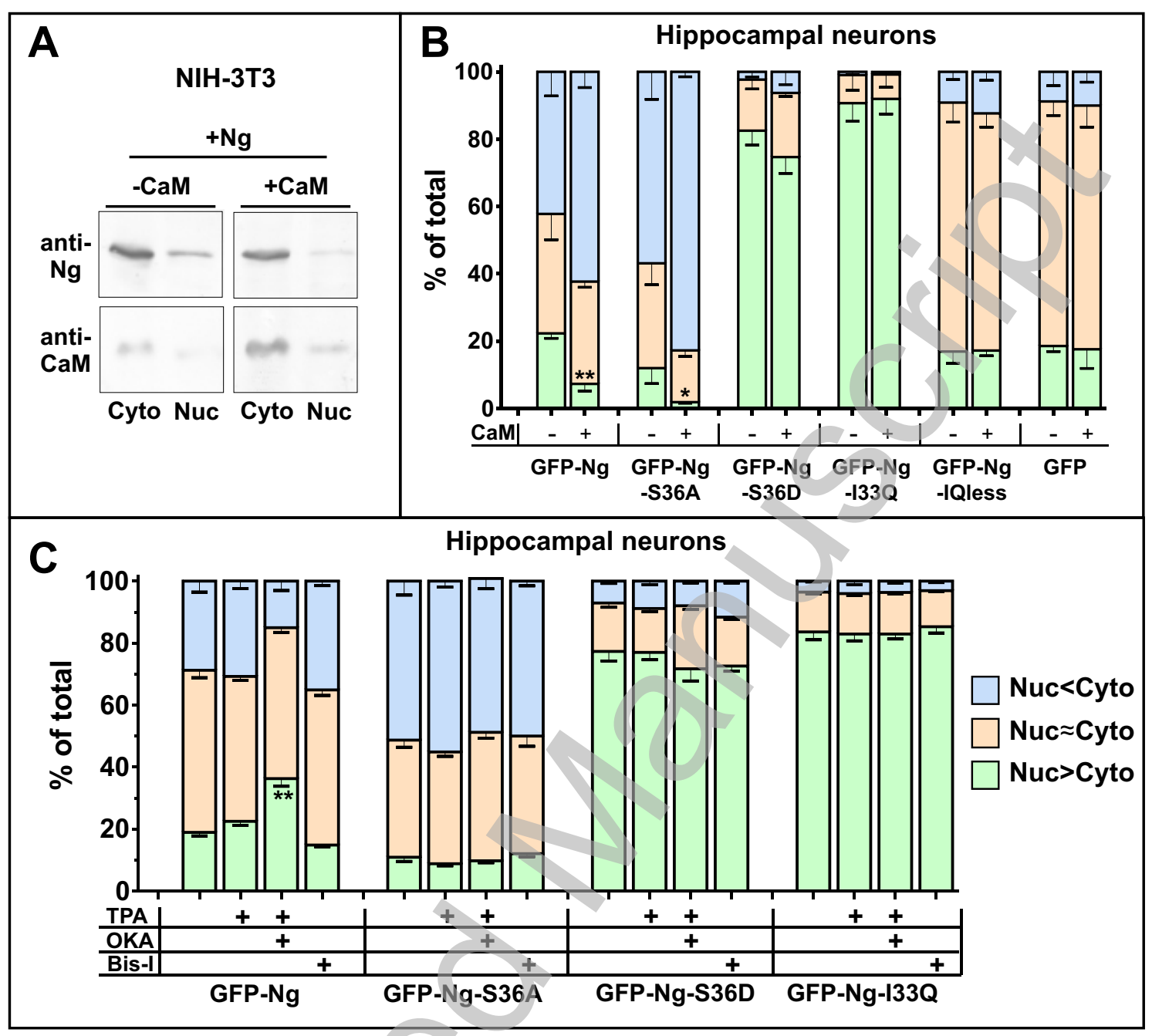

Figure 6

Licenced copy. Copying is not permitted, except with prior permission and as allowed by law. (C) 2009 The Authors Journal compilation (c) 2009 Portland Press Limited 


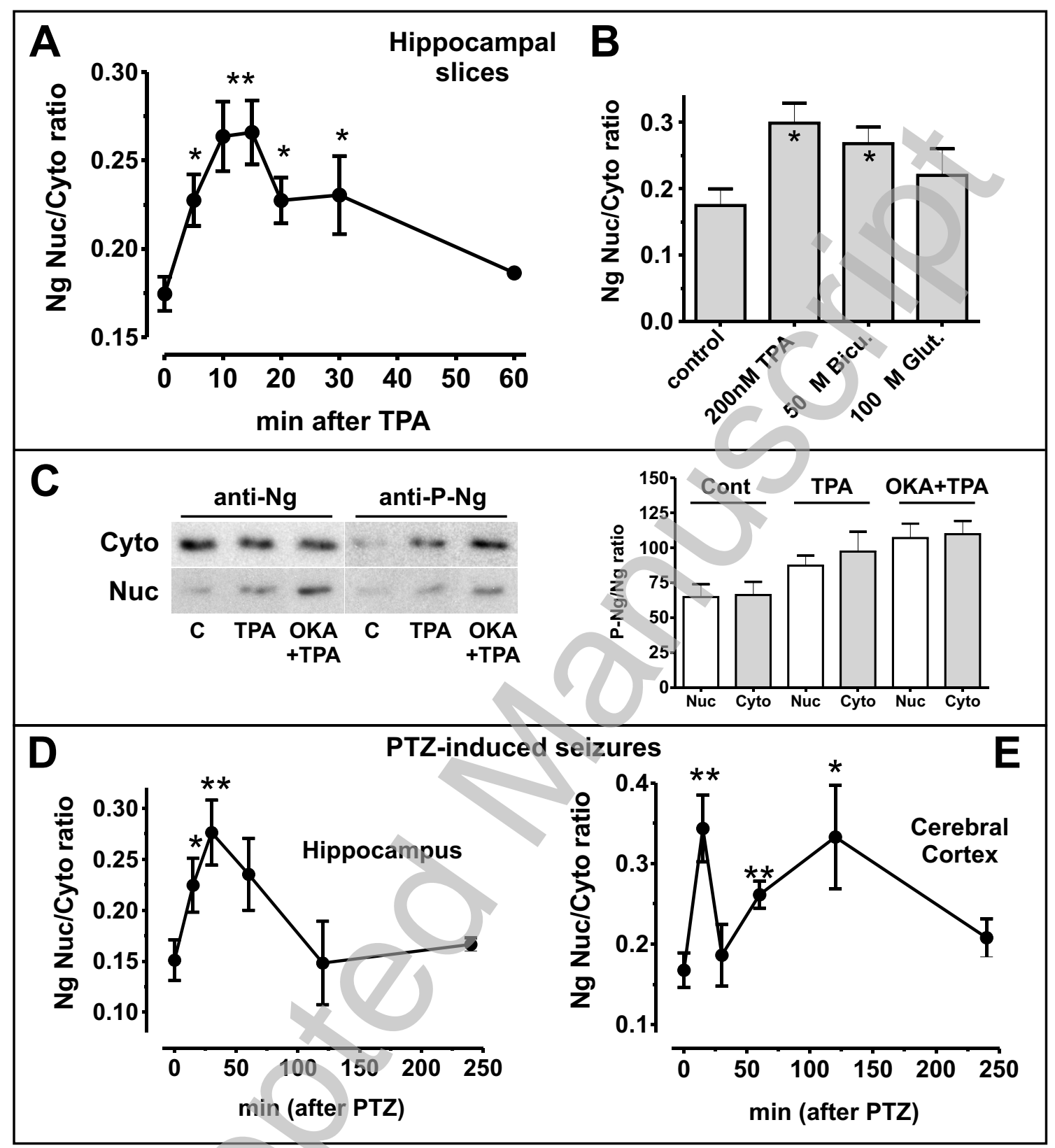

Figure 7

Licenced copy. Copying is not permitted, except with prior permission and as allowed by law. (C) 2009 The Authors Journal compilation (c) 2009 Portland Press Limited 